\title{
Health Beliefs, Stages of Change and Smoking Behaviour in Portuguese College Students
}

\author{
Filipa Pimenta, Isabel Leal and João Maroco \\ Instituto Superior de Psicologia Aplicada (ISPA), Health Psychology Research Unit, Portugal
}

\begin{abstract}
$\mathrm{T}^{\mathrm{T}}$ he aim of this cross-sectional study is to explore, in a sample of 380 college students, if there are any differences between regular, occasional and ex-smokers regarding health value, perceived health competence and self-efficacy to refrain from smoking. Stages of change are also assessed according to the transtheoretical model. There were no significant differences between groups regarding the health value. However, perceived health competence and self-efficacy (to refrain from smoking) were significantly different for the different smoking status and several stages of change. These findings provide new insights into how college student's health-related perceptions relate to smoking behaviour, which may help in the elaboration of smoking cessation interventions for this population.
\end{abstract}

Smoking has been evidenced by the World Health Organization (WHO) as the cause of a major percentage of avoidable and precocious mortality across developed countries. The association between smoking and the risk of developing a large range of diseases (namely, cardiovascular disease and lung cancer, as well as mouth, larynx, oesophagus and bladder tumours) has been emphasised by WHO (WHO, 2001). Even so, smokers who are informed about the impact that cigarette smoking can have on their health continue to smoke (Anatchkova, Velicer, \& Prochaska, 2006; Harmsen, Bischof, Brooks, Hohagen, \& Rumpf, 2006). Furthermore, although there have been many healthrelated initiatives to increase the awareness about the risk associated with smoking, there is a generalised absence of clearer evidence regarding the effectiveness of some of these initiatives in increasing smoking cessation intentions (Goldberg \& Fischhoff, 2000). The numbers related to cigarette consumption and prevalence of related disorders are a concern to health professionals and a research focus for many in the health sciences.

According to the Social Learning Theory (Bandura, 1999) people engage in certain behaviours (in a specific situation) if they perceive themselves as capable to do it and if that behaviour has a specific result that is valued by that person. Thus, if smokers value a probable consequence of smoking cessation (e.g., health maintenance or improvement) and perceive themselves as capable of refrain from smoking, they are likely to change their smoking behaviour (in a short period of time). By contrast, smokers who do not value their health and/or perceive themselves as less capable of managing their health are less probable to abstain from smoking and may not have the intention of changing smoking behaviour.

Thompson, Thompson, Thompson, Fredickson and Bishop (2003) underline that it is of crucial importance to find which characteristics influence smokers to stop cigarette consumption. Goldberg and Fischhoff (2000) have emphasised the need to explore factors that are related to risk behaviours, such as smoking behaviour, with the intention of finding the most effective way to promote the extinction of those behaviours.

Steptoe et al. (2002) have inferred that the increasing prevalence of smoking among college students has not been properly valued and explored. Literature has also evidenced that little is known about health beliefs, specifically in the filed of smoking behaviour (Halpern \& Warner, 1994). 
Regarding research developed with smokers and exsmokers and how people change their smoking behaviour, Prochaska and DiClemente's Transtheoretical Model is an important theoretical framework (Anatchkova et al., 2006; Boudreaux, Francis, Taylor, Scarinci, \& Brantley, 2003; Carosella, Ossip-Klein, \& Owens, 1999; Clarke \& Aish, 2002; Fava, Velicer, \& Prochaska, 1995; Haslam \& Draper, 2000; Kristeller, Rossi, Ockene, Goldberg, \& Prochaska, 1992; Norman, Velicer, Fava, \& Prochaska, 2000; Oakes, Chapman, Borland, Balmford, \& Trotter, 2004; Prochaska, DiClemente, \& Norcross, 1992; Prochaska, 1996; Prokhorov et al., 2003; Segan, Borland, \& Greenwood, 2002, 2005; Snow, Prochaska, \& Rossi, 1992). This model explores how people change their behaviour, structuring this change in five stages (precontemplation, contemplation, preparation, action and maintenance), each of them corresponding to a period of time and to intention and behaviour characteristics, common to all individuals in the same stage (Prochaska et al., 1992). The first stage (precontemplation) includes people who are not intending to stop smoking in a foreseeable future (i.e., 6 months); individuals in contemplation stage express the intention to stop smoking in the following 6 months; the next stage (preparation) is characterised by an intention to stop smoking in the short term (i.e., in 30 days); the action stage includes participants who have stopped smoking in the previous 6 months; and the last stage (maintenance) includes individuals who have been abstinent for more than 6 months. According to this model, people intentionally change their smoking behaviour as they shift from one stage of change to another, until they get to the last stage of change, when the smoking consumption is already absent. The progression throughout the five stages of changes is not always linear. Instead, the progression is made in a spiral movement, as in the smoking cessation process relapse is often observed, with the person returning to a prior stage of the model (Petrocelli, 2002; Prochaska et al., 1992; Ruggiero, Tsoh, Everett, Fava, \& Guise, 2000; Sutton, 2001).

The research on behaviour change has shown that a high perception of personal control (such as self-efficacy or internal locus of control) is associated with actions orientated to the maintenance of good health (Smith, Wallston, \& Smith, 1995). Since self-efficacy (i.e., the degree of belief that one has about being capable of doing something) has been strongly associated with behavioural change (Boudreaux, Carmack, Scarinci, \& Brantley, 1998; Etter, Bergman, Humair, \& Perneger, 2000; Marks, 1998; Norman, Velicer, Fava, \& Prochaska, 1998) and, therefore, several researchers have included the study of self-efficacy while exploring stages of change (Baer, Holt, \& Lichtenstein, 1986; Boudreaux et al., 1998; Boudreaux et al., 2003; Carosella et al., 1999; Fava et al., 1995; Guillot, Kilpatrick, Hebert, \& Hollander, 2004; Martinelli, 1999; Norman et al., 1998; Prochaska, Velicer, Guadagnoli, \&
Rossi, 1991; Prochaska et al., 1994; Prochaska et al., 2005; Segan et al., 2005; Snow et al., 1992).

Even though high self-efficacy has been reported to be associated with the latest stages of change (Marks, 1998; Prochaska et al, 1994; Prochaska et al., 2005), the results are not unanimous: Etter et al. (2000) have shown some studies where self-efficacy levels did not change across several stages of change.

If self-efficacy (specific for the ability to abstain from smoking) has a high value in predicting the cessation of a health-damaging behaviour such as smoking; then a dispositional measure of expectancy, namely perceived competence to manage health, can also be pertinent in the process of smoking cessation. Wallston (1992), who applied the social learning theory's principles to health behaviour, has emphasised that people's engagement in health behaviour is a function of two variables: (a) perceived health competence (i.e., the degree of belief that one's actions will influence his/her health status and the degree of confidence in one's capacity to undertake certain behaviours with the aim of maintaining or improving his/her health), and (b) health value (i.e., the degree of valorisation of one's health). According to this author, people's perceptions of the control that they have over their health can contribute to the maintenance/extinction of health-related behaviours (Wallston, 1992). Similarly, other authors corroborate that people who perceive low personal control over health are less likely to engage in health-promoting behaviours (Frank-Stromborg, Pender, Walker, \& Sechrist, 1990; Martinelli, 1999). Smith et al. (1995) emphasise that health status can have an impact on this perception: perceived health competence can vary between healthy people and people who have a disease.

Hanna, Faden and Dufour (1994) have inferred that in the field of substance abuse one cannot assume that different people value health in the same way. Moreover, Chassin Presson, Rose and Sherman (2001) have documented that smokers value health less than nonsmokers. Furthermore, Grube, McGree and Morgan (1986) have evidenced that, among college students, smokers attribute less value to the health concept than non-smokers.

Health-related perceptions have been associated with smoking cessation (Clarke \& Aish, 2002). As stated by Wallston (1992), people are more likely to engage in certain behaviours if the outcome is valued; thus health value should be systematically integrated in research about health-related behaviours (Lau, Hartman, \& Ware, 1986).

Chassin et al. (2001) have highlighted that it is only at the age of 20 that young adults increase the value attributed to their health; during high school years, although adolescents perceive cigarettes as dangerous to health, they do not value health in a significant way.

Lau et al. (1986) have evidenced that a significant valorisation of health, as well as an internal locus of control over health, can predict success in a smoking cessation program. Moreover, believing in personal 
control over health and highly valuing health are perceptions usually found in people with preventive behaviours towards their health. According to Kristiansen (1985) a valued health predicts by itself people's engagement in protective behaviors in relation to health.

The aim of this study was to explore significant differences regarding health value, perceived health competence and self-efficacy (to refrain from smoking) in a sample of college students that included regular smokers, occasional smokers and ex-smokers. We also assessed, according to the transtheoretical model, the stage of change (concerning the intention of stop smoking) in which participants were at the time of the data collection and if there were any differences between the five stages, regarding their health value, perceived health competence and self-efficacy.

\section{Method}

\section{Participants and Procedures}

This study was conducted at a Portuguese university in Lisbon, with 380 college students attending three courses: Psychology, Rehabilitation and Social Insertion, and Mental Health and Community Development, attending different years of the each course $(55.2 \%$ of all participants were first and second year students). The participants were approached by the researcher during classes and, after explaining that the research required participation of ever smokers (according to WHO's definition) (Etter \& Sutton, 2002), they were asked to complete several anonymous and confidential questionnaires.

All participants were classified according to their smoking status (regular smoker, ex-smokers and occasional smoker) and according to the stage of change of each participant (precontemplation, contemplation, preparation, action or maintenance).

The research included 278 regular smokers $(73.2 \%$ of the sample), 63 ex-smokers (16.6\%) and 39 occasional smokers $(10.3 \%)$. Most participants were in the two first stages of the transtheoretical model: 162 participants were in precontemplation (42.6\%) and 127 in the stage of contemplation (33.4\%). There were 12 participants in the stage of preparation (3.2\%), 26 in action (6.8\%) and 48 in maintenance (12.6\%) (5 participants were unable to be classified due to incorrect completion of the questionnaire). Of the total sample, $82.1 \%$ was female and the participants were, on average, 23 years old $(S D=$ $4.375)$ at the time of the assessment. Participants had started smoking, on average, by the age of $15(S D=$ $2.305)$ and the age at which ex-smokers had stopped smoking was $21(S D=4.046)$. Data collection took place between November 2005 and January 2006.

\section{Measures}

Each participant completed several questionnaires individually to assess stage of change, level of self-efficacy (to refrain from smoking), perceived health competence and health value. The questionnaire also included items related to smoking behaviours and sociodemographic characterisation.

Stages of change. Participants completed a measure of stage of change structured by Etter and Sutton (2002). The first question asks if the participant has smoked at less 100 cigarettes in his/her lifetime (which is the WHO's definition of ever smokers); the answer format is dichotomic $(y e s / n o)$. The following two questions address the intention of stop smoking in the short or long term (e.g., 'I smoke, but I seriously consider to quit smoking in the next 30 days.) and the occurrence of 24-hours quitting attempts in the previous year, based on the definition of stage of change according to the transtheoretical model.

Health value. Lau et al. (1986) have developed a 4-item scale (The Health Value Scale) to measure the value that people attribute to their health (e.g., 'If you don't have your health you don't have anything'). The answer scale ranges from 1 (strongly disagree) to 7 (strongly agree). The scale's internal consistency, given by Cronbach's alpha, is .62; in the original study of Lau et al. (1986), Cronbach's alpha was .67.

Smoking self-efficacy. Etter et al. (2000) have developed The Smoking Self-efficacy Questionnaire (SEQ-12) to assess the self-efficacy (to abstain from smoking) of current and former smokers, once facing several stimuli. The scale has two subscales, one for internal stimulus (e.g., 'when I feel nervous') and other for external ones (e.g., 'when I'm celebrating something'), each subscale has six items. The response options range from 'not at all sure' to 'absolutely sure' in a 5-point Likert-type scale. Cronbach's alpha was .92 for the internal stimuli subscale and .89 for external stimuli subscale (in the original study alphas were .95 and .94 respectively).

Perceived health competence. The Perceived Health Competence Scale (PHCS) is a domain-specific measure, developed by Smith et al. (1995); it has eight items that assess the degree to which people see themselves as capable of handling their health (e.g., 'I succeed in the projects I undertake to improve my health'). This instrument is of an intermediate level of specificity, between self-efficacy measures specific to a certain health behaviour and general competence perception instruments. The answering options are structured in a five-point Likert-type scale, ranging from strongly disagree to strongly agree. The PHCS had a Cronbach's alpha of .86 (in the original studies the alpha ranged from .82 to .90 ) (Smith et al., 1995).

Smoking habits and sociodemographic questionnaire. Participants were asked about past (for ex-smokers) or current (for regular and occasional smokers) smoking rate, the age at which they began smoking and the age at which they had stopped smoking (for ex-smokers). Demographic and personal variables such as gender, age, year attended at university, marital status, smoking behaviour of partner and presence of a disease were also addressed. 


\section{Analysis}

Statistically significant differences between smoking status groups and stages of change regarding health value, perceived health competence and self-efficacy to abstain from smoking were evaluated by a one-way ANOVA or by the Kruskal-Wallis ANOVA on ranks (when the assumptions of the one-way ANOVA were not met). Tukey's HSD or Fisher's LSD on ranks were applied, respectively, a posteriori to identify which groups differed significantly after ANOVA or KruskalWallis significance testing. A Mann-Whitney test was also used to evaluate differences in perceived health competence between participants who had a disease and those who did not have a disease at the time of assessment. Finally, the association of perceived health competence and health value was evaluated by Spearman correlation coefficient.

All statistical data analysis were performed with SPSS, version 14.0 and statistical significance was evaluated for $p=.05$.

\section{Results}

\section{Differences Between Smoking Status in Relation to Health} Value, Perceived Health Competence and Self-efficacy

Mean health value for regular smokers was $5.5(S D=.96)$; occasional smokers had a mean health value of $5.8(S D=$ $.87)$ and in ex-smokers the mean was of $5.6(S D=.87)$, as evidenced in Figure 1. However, there were no statistically significant differences between regular, occasional and ex-smokers regarding to health value, $F(2,377)=$ $1.594, p=.205$.

Regular smokers displayed a mean perceived health competence of $3.6(S D=.65)$; in relation to the same variable, ex-smokers had a mean value of $4.0(S D=.65)$ and for occasional smokers it was $3.8(S D=.54)$, as evidenced in Figure 2. There were significant differences between the two smoking status concerning the perceived health competence, $F(2,377)=9.193, p<.001$, with significant differences detected between ex-smokers and regular smokers, $M D_{E x-s-\text { Reg.S.S. }}=0.358, p<.001$.

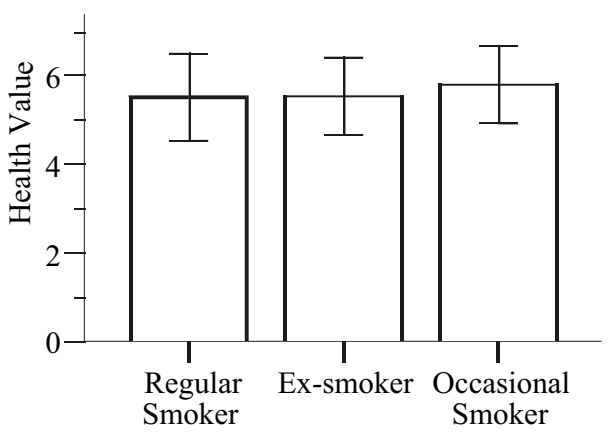

Smoking Status

\section{Figure 1}

Health value according to smoking status (bars represent the mean $\pm 1 S D$ ).

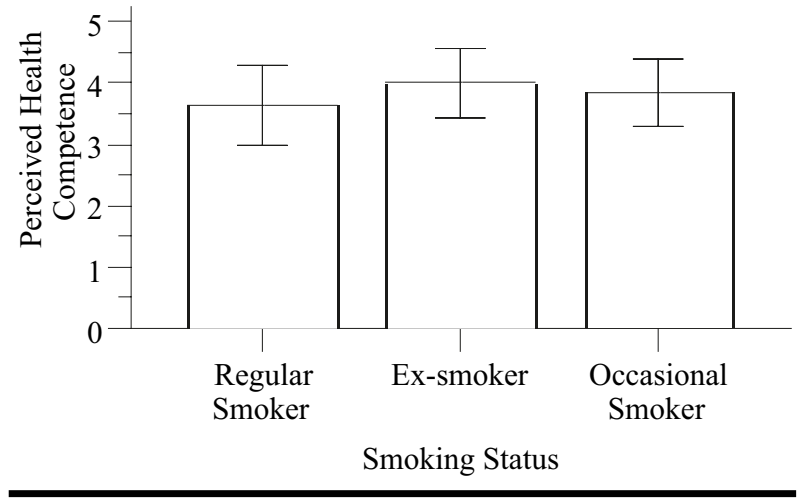

Figure 2

Perceived health competence according to smoking status (bars represent the mean $\pm 1 S D)$.

The following self-efficacy mean values (for internal stimuli) were observed: $2.3(S D=.94)$ for regular smokers, $4.3(S D=.96)$ for ex-smokers and $3.5(S D=1.00)$ for occasional smokers, as indicated in Figure 3. In relation to self-efficacy towards external stimuli the mean values were equal to $2.2(S D=.95)$ for regular smokers, $4.1(S D=.97)$ for ex-smokers and $3.4(S D=.96)$ for occasional smokers, as indicated in Figure 4.

Statistically significant differences were also observed between participants regarding the self-efficacy (to abstain from smoking) towards internal, $F(2,376)=129.309$, $p<.001$, and external stimuli, $F(2,376)=116.121, p<.001$. Post-hoc multiple mean comparison, using the Tukey's test, found significant differences in the self-efficacy towards internal stimuli between ex-smokers and both occasional smokers, $M D_{E x-\text { s. }-O c c . S .}=0.716, p<.001$, and regular smokers, $M D_{\text {Ex-s.-Reg.S. }}=2.002, p<.001$, occasional smokers also differed significantly from regular smokers, $M D_{\text {Occ.S.Reg.S. }}=1.286, p<.001$.

Concerning self-efficacy towards external stimuli, posthoc multiple mean comparison (with Tukey's test) found significant differences between the three groups:

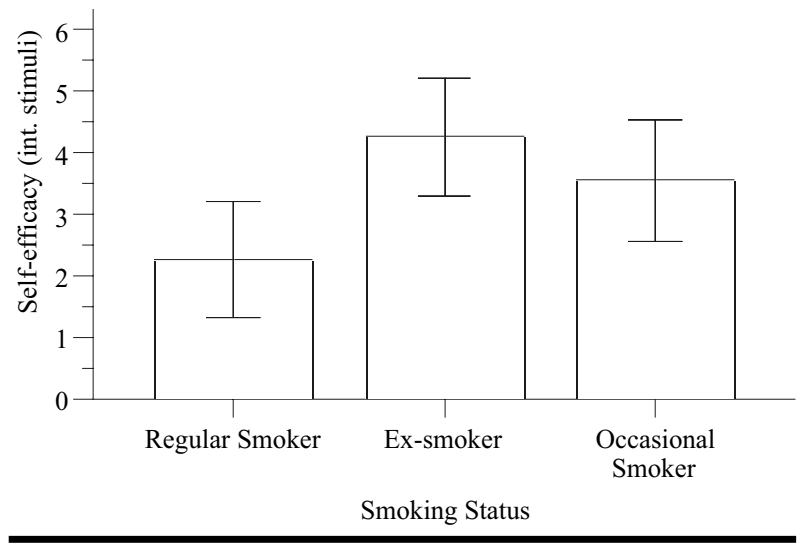

Figure 3

Self-efficacy (internal stimulus) according to smoking status (bars represent the mean $\pm 1 S D$ ). 
ex-smokers differ from occasional smokers, $M D_{\text {Ex-s.-Occ.S }}=$ $0.677, p=.002$, and regular smokers, $M D_{E x-\text { s. }- \text { Reg.s. }}=1.910$, $p<.001$. Similarly, occasional smokers also varied significantly, when compared with regular smokers, $M D_{\text {Occ.S.-Reg.S. }}=1.234, p<.001$.

\section{Differences Between Stages of Change in Relation to Health Value, Perceived Health Competence and Self-efficacy}

The mean health value was analysed for each one of the five stages of change: in precontemplation it was 5.5 (SD $=.99)$, for contemplation the mean was of $5.6(S D=.89)$, for preparation $5.9(S D=.91)$, in the stage of action 5.8 $(S D=.94)$ and in maintenance was $5.4(S D=.88)$, as represented in Figure 5.

There were no significant differences in the health value between the five stages of change, $\chi^{2}(2)=6.100$, $p=.192$, as evaluated by the Kruskal-Wallis test.

The perceived health competence mean values observed were the following: $3.7(S D=.62)$ in precontemplation, $3.6(S D=.67)$ in contemplation, $3.9(S D$ $=.52)$ in preparation, $3.9(S D=.49)$ in action and, finally, $4.0(S D=.62)$ mean value in the stage of maintenance (Figure 6).

Concerning perceived health competence, there are significant differences between several stages of change, $\chi^{2}(2)$ $=17.122, p=.002$. As evidenced with posthoc multiple mean comparison (performed with Fisher's LSD method on ranks), participants in maintenance differed from those in precontemplation, $M D_{\text {Maint.-Precont. }}=58.463, p=.001$, and in contemplation stages, $M D_{\text {Maint-Cont. }}=65.056, p<.001$.

There are also significant differences between people in the action stage and individuals in the contemplation stage, $M D_{\text {Act.Cont. }}=65.056, p=.037$, regarding perceived health competence.

In relation to self-efficacy to refrain from smoking, specifically towards internal stimuli, participants in the precontemplation stage had a mean value of 2.3 $(S D=1.01)$, in contemplation of $2.4(S D=.92)$, students in preparation displayed a mean value equal to 3.6

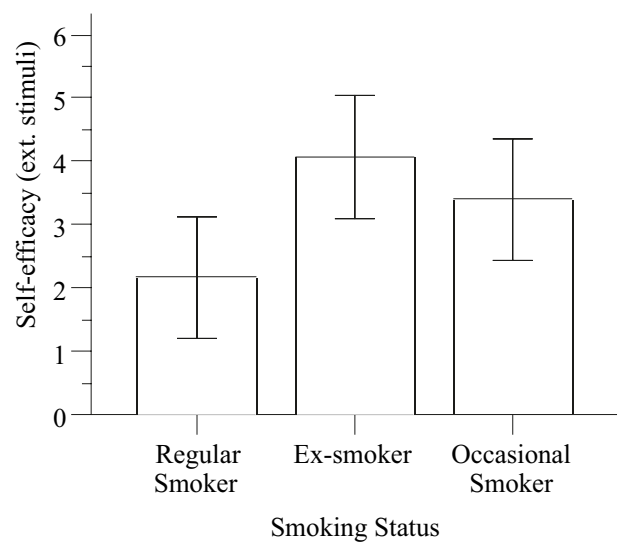

Figure 4

Self-efficacy (external stimuli) according to smoking status (bars represent the mean $\pm 1 S D)$.

$(S D=.94)$, in action stage of $3.8(S D=1.00)$ and in the last stage $4.4(S D=.97)$, as evidenced in Figure 7 .

Regarding the mean values of external stimuli selfefficacy, values were observed equal to $2.2(S D=1.03)$ in precontemplation, $2.3(S D=.97)$ in contemplation, 2.7 $(S D=.75)$ in preparation, $3.6(S D=.86)$ in action and finally $4.3(S D=.96)$ in maintenance stage (Figure 8$)$. Significant differences were observed between stages of change, towards both internal, $\chi^{2}(2)=119.359, p<.001$, and external stimuli, $\chi^{2}(2)=112.418, p<.001$.

Posthoc multiple mean comparison, regarding the self-efficacy towards internal stimuli, found that participants in maintenance differ significantly from those in precontemplation, $M D_{\text {Maint.-Precont. }}=171.454, p<.001$, and contemplation, $M D_{\text {Maint-Cont. }}=153.001, p<.001$. Likewise, significant differences were also observed between action stage and precontemplation, $M D_{\text {Act.-Precont. }}=$ $132.453, p<.001$, and contemplation stages, $M D_{\text {Act.-Cont. }}$ $=114.001, p<.001$. In the same way, preparation stage differed significantly from precontemplation, $M D_{\text {Prep. }}$

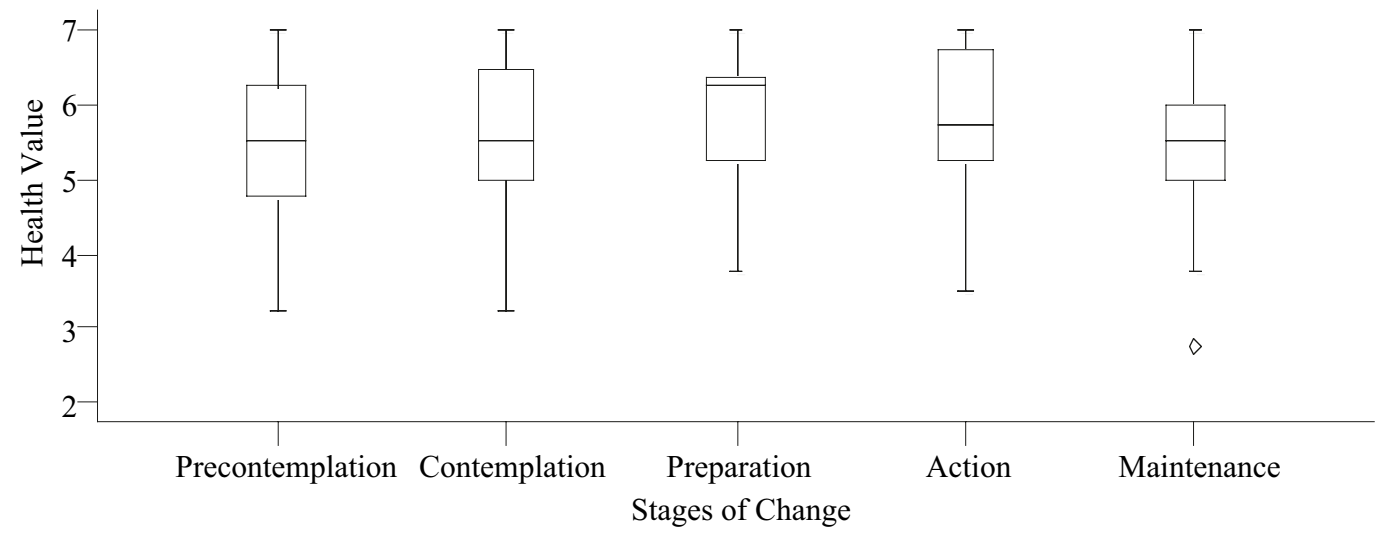

Figure $\mathbf{5}$

Health value by stages of change. 


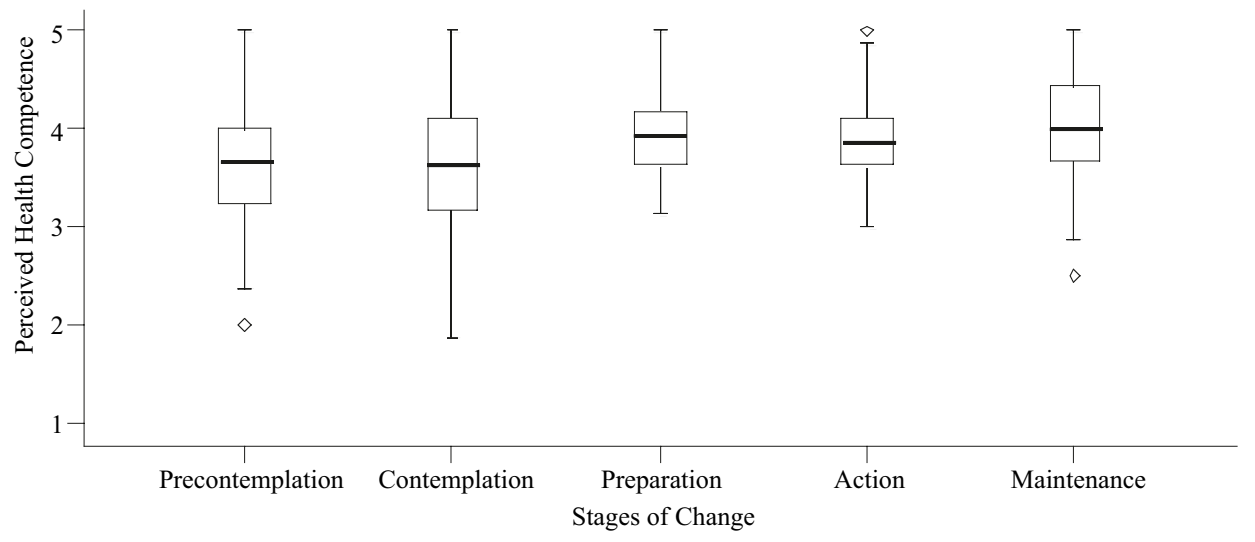

\section{Figure 6}

Perceived health competence according to stages of change.

Precont. $=121.228, p<.001$, and contemplation stages, $M D_{\text {Prep.-Cont. }}=102.776, p<.001$, regarding self-efficacy towards internal stimuli.

In relation to self-efficacy towards external stimuli there were statistically significant differences between the maintenance stage and precontemplation, $M D_{\text {Maint. }}$ Precont. $=170.276 ; p<.001$, contemplation, $M D_{\text {Maint.-Cont. }}=$ $151.804, p<.001$, and preparation, $M D_{\text {Maint.-Prep. }}=$ $110.577, p<.001$, stages. Similarly, between action stage and precontemplation, $M D_{\text {Act.Precont. }}=134.613, p<.001$, contemplation, $M D_{\text {Act.-Cont. }}=116.141, p<.001$, and preparation, $M D_{\text {Act.-Prep. }}=74.913, p=.021$, stages it also identified significant differences regarding self-efficacy towards external stimuli. Finally, participants in preparation stage also differed significantly from those in precontemplation stage, $M D_{\text {Prep.-Precont. }}=59.699, p=.031$.

Concerning health competence as perceived by participants with and without a disease, it was observed that individuals without disease perceived themselves as more competent to deal with their health than those with a disease, $Z=3058.500, p<.001$.

To explore the correlation between perceived health competence and health value a Spearman correlation test was applied. The correlation, although statistically significant, was weak $\left(r_{s}=0.149, p=.01\right)$.

\section{Discussion}

Although literature has evidenced that people who change behaviours in order to maintain or improve their health usually value their health significantly, in the present study we saw no significant differences between people who had stopped a health-threatening behaviour (exsmokers) and the ones who display that behaviour (regular and occasional smokers) in the value attributed to their health (all groups have a mean equal or above 5.5). Likewise, there were also no differences in the health value of participants across the five stages of change.

In the current smokers' case, like health, cigarette consumption can also be highly valued (or even more valued than health itself), since it is probably perceived as having significant gains (such as social desirability, anxiety reduction in everyday life, avoidance of nicotine withdrawal symptoms, etc.) and therefore maintained and, at the same time, placing a high value on health. Regarding ex-smokers, they can have stopped smoking,

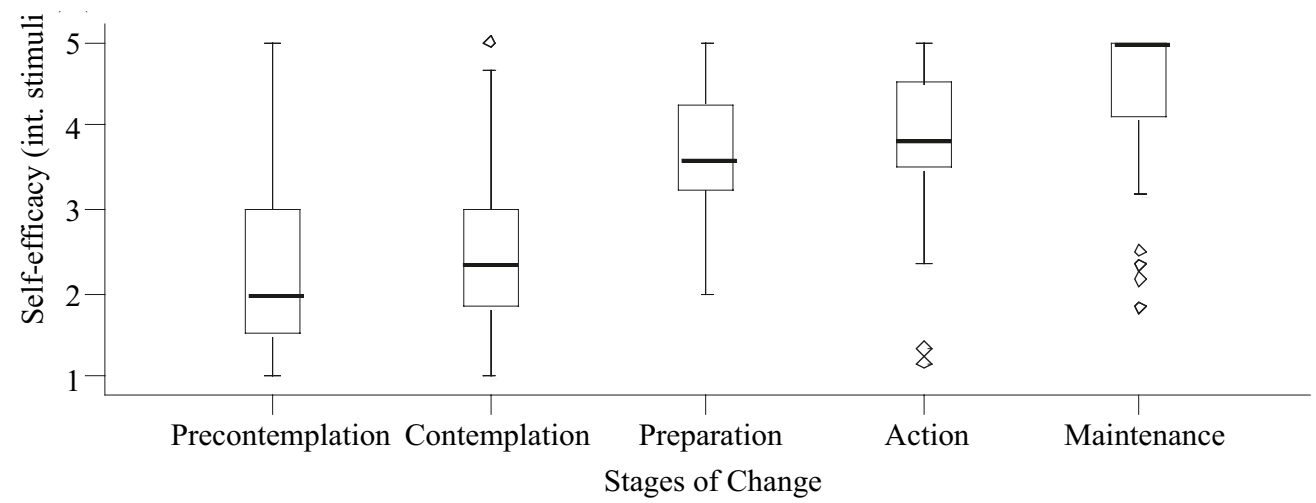

Figure 7

Self-efficacy (internal stimuli) according to stages of change. 


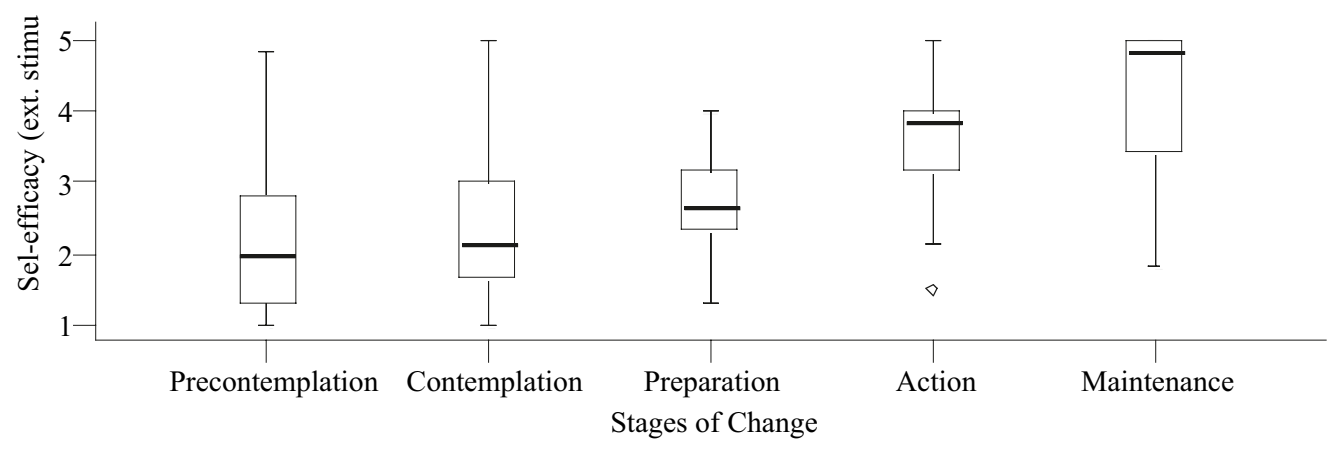

Figure 8

Self-efficacy (external stimuli) according to stages of change.

not for health reasons, but for other motives and hence they do not place a higher value on health than other people who smoke (regularly or occasionally).

According to Festinger's (1957) cognitive dissonance theory (Oakes et al., 2004), people need cognitive consonance between behaviours and attitudes: if they have the belief that smoking is harmful for themselves then the consumption behaviour will create a discomfort that will reduce the chance of enjoying associated gains.

As stated by Chapman et al. (1993) and Hermand, Mullet and Coutelle (2001), smokers agree on the danger that smoking poses to health. However, they underestimate the negative consequences that smoking can have on their personal health (Chapman et al., 1993; Chassin et al., 2001; Moran, Glazier, \& Armstrong, 2003; Oakes et al., 2004; Willaing, Jorgensen, \& Iversen., 2003) and perceived themselves as less vulnerable than other people to the hazards of smoking (Cummings, Hyland, Giovino, Hastrup, Bauer, \& Bansal, 2003; Prokhorov et al., 2003). It can also be hypothesised that students do not have accurate information about the harmful consequences of smoking, specifically students in the first year of college, as evidenced by Sejr and Osler (2002).

Regarding perceived health competence, this study evidences that ex-smokers perceive themselves as more competent to deal with their health in general than regular smokers (as illustrated in Figure 2). Significant differences are also seen between the first stages of the transtheoretical model and the last ones: participants who are in the two last stages have significant higher perceived health competence than those in the two first stages (Figure 6).

According to the application of social learning theory principles to the health context, perceived health competence would be associated with health value. Our data suggest that the association between the two variables is weak, although statistically significant $\left(r_{\mathrm{s}}=0.149\right.$, $p=.01)$. Hence, people who perceived themselves as poorly competent to manage their health do not necessary value their health less than people who perceived themselves as highly competent to deal with health in general. In the present study, people who feel less competent to deal with their health, value health as much as those who perceived themselves as highly competent to manage health. Also in relation to perceived health competence, the analysis shows that people who had a disease at the time of the assessment perceived themselves as significantly less capable to manage their health in general than those participants who did not have any clinical diagnosis. This conclusion meets what Smith et al. (1995) have emphasised in the past: perceived health competence can be associated with health status.

Regarding the self-efficacy to refrain from smoking, there are significant differences between smokers (regular and occasional) and ex-smokers: ex-smokers differ significantly from occasional smokers who, in turn, differ significantly from regular smokers in relation to self-efficacy towards both internal and external stimuli. In concordance with the vast majority of literature, ex-smokers display significantly higher levels of self-efficacy, as compared to smokers (Figures 3 and 4).

The same findings were also observed when comparing the five stages of change: participants in the last two stages (maintenance and action) display a self-efficacy significantly higher than those in the first two stages (precontemplation and contemplation) (Figures 7 and 8). This is congruent with what Wallston (1992) underlines: the engagement in health-protective behaviours and the extinction of health-threatening ones are associated with competence and efficacy perceptions to deal with those behaviours.

It is interesting to notice that in relation to selfefficacy (towards internal stimuli), individuals in the preparation stage differed significantly from participants in the previous stage (contemplation); but, regarding self-efficacy to face external stimuli, people in preparation stage differed significantly from individuals in the next one (action).

Therefore, participants in the preparation stage showed higher internal stimuli self-efficacy than participants in previous stage, but are less capable to refrain from smoking when facing external stimuli, as compared 
with participants in the action stage. It is also worthy to mention the fact that some occasional smokers have classified themselves as being in action (17.95\%) and maintenance $(12.82 \%)$ stages. According to the transtheoretical model these two stages include only ex-smokers, but, as other authors have evidenced (e.g., Etter \& Sutton, 2002), there are occasional smokers who include themselves in the two later stages of the model. This discrepancy between theory and reality may be due to the dichotomous conceptualisation of smoking behaviour (smoker vs. ex-smoker) made by the model. However, in practice, smoking behaviour seems to vary on a continuum, where people fluctuate in relation to their cigarette consumption pattern.

\section{Conclusions}

Interventions aiming towards smoking cessation in college students should take into account health-related perceptions and domain-specific self-efficacy, targeting also what can be perceived as immediate benefits and valued consequences associated to cessation.

As young adults value health independently of displaying a health-threatening behaviour such as smoking, it can be pertinent to identify risk perceptions and information accuracy about smoking consequences to their (and significant others') health. On the other hand, finding short-term benefits of smoking cessation (maintaining/improving appearance — pleasant breath and get rid of clothing odours - apply cigarette money towards other desired things) may help young adults to take action. Interdiction of smoking inside university facilities can also have a significant impact on decreasing smoking rates among college students.

Further investigations targeting other beliefs with the aim of continuing to identify what makes smokers keep on smoking and ex-smokers stop smoking appears to be relevant given the high prevalence of cigarette consumption among young adults.

\section{Acknowledgments}

We gratefully acknowledge the authors of the four questionnaires who gave authorisation to translate and use them in the present research and also to all ISPA's teachers who kindly allowed us to talk to the students during their classes.

\section{References}

Anatchkova, M., Velicer, W.F., \& Prochaska, J.O. (2006). Replication of subtypes for smoking cessation within the precontemplation stage of change. Addictive Behaviors, 31(7), 1101-1115.

Baer, J.S., Holt, C.S., \& Lichtenstein, E., (1986). Self-efficacy and smoking reexamined: Construct validity and clinical utility. Journal of Consulting and Clinical Psychology, 54(6), 846-852.

Bandura, A. (1999). A sociocognitive analysis of substance abuse: An agentic perspective. Psychological Science, 10(3), 214-217.
Boudreaux, E., Carmack, C.L., Scarinci, I.C., \& Brantley, P.J., (1998). Predicting smoking stage of change among a sample of low socioeconomic status, primary care outpatients: replication and extension using decisional balance and self-efficacy theories. International Journal of Behavioral Medicine, 5(2), 148-165.

Boudreaux, E.D., Francis, J.L., Taylor, C.L. C., Scarinci, I.C., \& Brantley, P.L. (2003). Changing multiple health behaviors: smoking and exercise. Preventive Medicine, 36, 471-478.

Carosella, A.M., Ossip-Klein, D.J., \& Owens, C.A. (1999). Smoking attitudes, beliefs and readiness to change among acute and long term care inpatients with psychiatric diagnoses. Addictive Behaviors, 24(3), 331-344.

Chapman, S., Wong, W.L., \& Smith, W. (1993). Self-exempting beliefs about smoking and health: Differences between smokers and ex-smokers. American Journal of Public Health, 83(2), 215-219.

Chassin, L., Presson, C.C., Rose, J.S., \& Sherman, S.J. (2001). From adolescence to adulthood: Age-related changes in beliefs about cigarette smoking in a midwest community sample. Health Psychology, 20(5), 377-386.

Clarke, K.E., \& Aish, A. (2002). An exploration of health beliefs and attitudes of smokers with vascular disease who participate in or decline a smoking cessation program. Journal of Vascular Nursing, 20(3), 96-105.

Cummings, K.M., Hyland, A., Giovino, G.A., Hastrup, J.L., Bauer, J.E., \& Bansal, M.A. (2003). Are smokers adequately informed about the health risks of smoking and medicinal nicotine? Nicotine \& Tobacco Research, 6(3), 333-340.

Etter, J.F., Bergman, M.M., Humair, J.P., \& Perneger, T.V. (2000). Development and validation of a scale measuring self-efficacy of current and former smokers. Addiction, 95(6), 901-913.

Etter, J.F., \& Sutton, S. (2002). Assessing 'stage of change' in current and former smokers. Addiction, 97, 1171-1182.

Fava, J.L., Velicer, W.F., \& Prochaska, J.O., (1995). Applying the transtheoretical model to a representative sample of smokers. Addictive Behaviors, 20(2), 189-203.

Frank-Stromborg, M., Pender, N.J., Walker, S.N., \& Sechrist, K.R. (1990). Determinants of health promoting lifestyle in ambulatory cancer patients. Social Science and Medicine, 31(10), 1159-1168.

Goldberg, J., \& Fischhoff, B. (2000). The long-term risks in the short-term benefits: Perceptions of the potentially addictive activities. Health Psychology, 19(3), 299-303.

Grube, J.W., McGree, S.T., \& Morgan, M. (1986). Beliefs related to cigarette smoking among Irish college students. International Journal of the Addictions, 21(6), 701-706.

Guillot, J., Kilpatrick, M., Hebert, E., \& Hollander, D., (2004). Applying the transtheoretical model to exercise adherence in clinical settings. American Journal of Health Studies, 19(1), 1-10.

Halpern, M.T., \& Warner, K.E. (1994). Differences in former smokers' beliefs and health status following smoking cessation. American Journal of Preventive Medicine, 10(1), 31-38.

Hanna, E.Z., Faden, V.B., \& Dufour, M.C. (1994). The motivational correlates of drinking, smoking and illicit drug use during pregnancy. Journal of Substance Abuse, 6, 155-167. 
Harmsen, H., Bischof, G., Brooks, A., Hohagen, F., \& Rumpf, H.-J. (2006). The relationship between impaired decision-making, sensation seeking and readiness to change in cigarette smokers. Addictive Behaviors, 31(4), 581-592.

Haslam, C., \& Draper, E. (2000). Stage of change is associated with assessment of the health risks of maternal smoking among pregnant women. Social Science \& Medicine, 51, 1189-1196.

Hermand, D., Mullet, E., \& Coutelle, B. (2001). Perception of the combined effect of smoking and alcohol on health. The Journal of Social Psychology, 135(2), 167-174.

Kristeller, J.L., Rossi, J.S., Ockene, J.K., Goldberg, R., \& Prochaska, J.O. (1992). Processes of change in smoking cessation: A cross-validation study in cardiac patients. Journal of Substance Abuse, 4(3), 263-276.

Kristiansen, C.M. (1985). Value correlates of preventive health behavior. Journal of Personality and Social Psychology, 49, 748-758.

Lau, R.R., Hartman, K.A., \& Ware, J.E. (1986). Health as a value: methodological and theoretical considerations. Health Psychology, 5(1), 25-43.

Marks, D.F. (1998). Addiction, smoking and health: developing policy-based interventions. Psychology, Health and Medicine, 3(1), 97-112.

Martinelli, A.M. (1999). An explanatory model of variables influencing health promotion behaviors in smoking and nonsmoking college students. Public Health Nursing, 16(4), 263-269.

Moran, S., Glazier, G., \& Armstrong, K. (2003). Women smokers' perceptions of smoking-related health risks. Journal of Women's Health, 12(4), 363-371.

Norman, G.J., Velicer, W.F., Fava, J.L., \& Prochaska, J.O. (1998). Dynamic typology clustering within the stages of change for smoking cessation. Addictive Behaviors, 23(2), 139-153.

Norman, G.J., Velicer, W.F., Fava, J.L., \& Prochaska, J.O. (2000). Cluster subtypes within stages of change in a representative sample of smokers. Addictive Behaviors, 25(2), 183-204.

Oakes, W., Chapman, S., Borland, R., Balmford, J., \& Trotter, L. (2004). 'Bulletproof skeptics in life's jungle': Which selfexempting beliefs about smoking most predict lack of progression towards quitting? Preventive Medicine, 39, 776-782.

Petrocelli, J.V. (2002). Processess and stages of change: Counseling with the transtheoretical model of change. Journal of Counseling and Development, 80, 22-30.

Prochaska, J.O., Velicer, W.F., Guadagnoli, E., \& Rossi, J.S. (1991). Patterns of change: Dynamic topology applied to smoking cessation. Behavioral Research, 26(1), 83-107.

Prochaska, J.O., DiClemente, C.C., \& Norcross, J. (1992). In search of how people change: Application to addictive behaviors. American Psychologist, 47(9), 1102-1114.

Prochaska, J.O., Velicer, W.F., Rossi, J.S., Goldstein, M.G., Marcus, B.H., Rakowski, W. et al. (1994). Stages of change and decisional balance for 12 problem behaviors. Health Psychology, 13, 39-46.
Prochaska, J.O. (1996). A stage paradigm for integrating clinical and public health approaches to smoking cessation. Addictive Behaviors, 21(6), 721-732.

Prochaska, J.M., Paiva, A.L., Padula, J.A., Prochaska, J.O., Montgomery, J.E., Hageman, L. et al. (2005). Assessing emotional readiness for adoption using the transtheoretical model. Children and Youth Services Review, 27, 135-152.

Prokhorov, A.V., Warneke, C., Moor, C., Emmons, K.M., Jones, M.M., Rosenblum, C. et al. (2003). Self-reported health status, health vulnerability, and smoking behavior in college students: Implications for intervention. Nicotine and Tobacco Research, 5(4), 545-552.

Ruggiero, L., Tsoh, J.Y., Everett, K., Fava, J.L., \& Guise, B.J. (2000). The transtheoretical model of smoking: Comparison of pregnant and non-pregnant smokers. Addictive Behaviors, 25(2), 239-251.

Segan, C.J., Borland, R., \& Greenwood, K.M. (2002). Do transtheoretical model measures predict the transition from preparation to action in smoking cessation? Psychology and Health, 17(4), 417-435.

Segan, C.J., Borland, R., \& Greenwood, K.M. (2006). Can transtheoretical model measures predict relapse from the action stage of change among ex-smokers who quit after calling a quitline? Addictive Behaviors, 31(3), 414-428.

Sejr, H.S., \& Osler, M. (2002). Do smoking and health education influence student nurses' knowledge, attitudes and professional behavior? Preventive Medicine, 34, 260-265.

Smith, M.S., Wallston, K.A., \& Smith, C.A. (1995). The development and validation of the perceived health competence scale. Health Education Research: Theory of Practice, 10(1), 51-64.

Snow, M.G., Prochaska, J.O., \& Rossi, J.S., (1992). Stages of change for smoking cessation among former problem drinkers: A cross-sectional analysis. Journal of Substance Abuse, 4(2), $107-116$.

Steptoe, A., Wardle, J., Cui, W., Baban, A., Glass, K., Pelzer, K., Tsuda, A., \& Vinck, J. (2002). An international comparison of tobacco smoking, beliefs and risk awareness in university students from 23 countries. Addiction, 97, 1561-1571.

Sutton, S. (2001). Back to the drawing board? A review of applications of the trantheoretical model to substance use. Addiction, 96, 175-186.

Thompson, B., Thompson, L.A., Thompson, J., Fredickson, C., \& Bishop, S. (2003). Heavy smokers: a qualitative analysis of attitudes and beliefs concerning cessation and continued smoking. Nicotine \& Tobacco Research, 5(6), 923-933.

Wallston, K.A. (1992). Hocus-pocus, the focus isn't strictly on locus: Rotter's social learning theory modified for health. Cognitive Therapy and Research, 16(2), 183-199.

WHO, Department of Mental Health and Substance Dependence. (2001). Encouraging people to stop smoking. Geneva: WHO.

Willaing, I., Jorgensen, T., \& Iversen, L. (2003). How does individual smoking behaviour among hospital staff influence their knowledge of the health consequences of smoking? Scandinavian Journal of Public Health, 31, 149-155. 